\title{
Estimating the Turkish Sectoral Market Returns via Arbitrage Pricing Model under Neural Network Approach
}

\author{
Fazıl Gökgöz ${ }^{1} \&$ Özge Sezgin-Alp ${ }^{2}$ \\ ${ }^{1}$ Faculty of Political Sciences, Department of Management, Quantitative Methods Division, Ankara University, \\ Ankara, Turkey \\ ${ }^{2}$ Faculty of Commercial Sciences, Department of Accounting and Financial Management, Başkent University, \\ Ankara, Turkey
}

Correspondence: Fazıl Gökgöz, Ankara University, Faculty of Political Sciences Department of Management, Quantitative Methods Division 06600 Cebeci, Ankara, Turkey. E-mail: fgokgoz@ankara.edu.tr

Received: September 24, 2014

Accepted: October 30, 2014

Online Published: December 25, 2014

doi:10.5539/ijef.v7n1p154

URL: http://dx.doi.org/10.5539/ijef.v7n1p154

\begin{abstract}
As an alternative to Capital Asset Pricing Model (CAPM), Arbitrage Pricing Theory $(A P T)$ is crucial in analyzing practical asset prices. APT provides a kind of multi factor market model which describes the expected returns with respect to macro-economic factors. In multifactor financial modeling, generally the traditional linear models are preferred. However, in the finance literature there are researches indicating the non-stationary and non-linearity of asset prices. For this purpose, in this paper the Artificial Neural Network (ANN) with Feed Forward Back Propagation algorithm has been employed to estimate the expected returns of the main sector indices of the İstanbul Stock Exchange, an emerging stock market, by using their relations with macroeconomic variables over 2003 and 2012 period. The forecasting ability of the ANN model is accessed using in sample and out of sample means square error (MSE) statistics and hypothesis test statistics testing whether there are differences between predicted returns and real returns. The results have revealed that the methodology based on ANN has a significant ability to estimate the different sectors in Turkish stock market with APT approach.
\end{abstract}

Keywords: multifactor financial models, artificial neural networks, financial modeling, emerging markets, Turkey

\section{Introduction}

In finance literature the most popular problem is to predict the risky asset prices. Modern financial theory about risk assets has been started by the study of Harry Markowitz in 1952. Markowitz's (1952) study has a benchmarking role since it explains the preferences of investors for understanding the risk factors. The next step should be to determine the market equilibrium conditions and the risky asset prices. This theory is firstly introduced by Sharpe (1964), Lintner (1965) and Mossin (1966) with Capital Asset Pricing Model (CAPM). In CAPM the non-diversifiable risk of an asset is represented by the asset's sensitivity to the market portfolio.

CAPM is one of the most popular asset pricing models, however due to its strict assumptions; the model includes only the systematic risk for the given portfolio. One of the studies that are alternative to CAPM is Arbitrage Pricing Theory (APT) which was introduced by Ross (1976). As compared to CAPM, it has fewer, less restrictive and reasonable assumptions. Within the framework of APT, the risky asset price is specified with macroeconomic factors as the parts of systematic risk.

Besides, APT is an alternative asset pricing approach to CAPM. In further, it depends on law of one price which implies two assets that always have the same pay-offs must have the same price. In APT the risky asset price is specified with many macroeconomic factors as the parts of systematic risk. According to finance theory, firm specific risk can be diminished with well diversified portfolios. Thus, the important risk for the investors is systematic risk and can be represented by different economic factors.

Although, APT theory was first introduced by Ross (1976), it is empirically developed by Roll and Ross (1980), Huberman (1982), Chemberlain and Rothschild (1982), Chen, Roll and Ross (1986), Fama (1990) and Ferson (1991). 
There are other multifactor models using different number of macroeconomic factors based on APT by using traditional statistical techniques in the literature. Their results show that the stock market and economic factors are related. These papers are generally for developed countries but there are limited researches of APT and its applications to emerging markets. However, asset pricing in emerging markets is challenging due to their complexities and inefficient structures (Altay \& Satman, 2005).

The emerging markets are more likely to be influenced by local information (Harvey, 1995). In addition, the Artificial Neural Network $(A N N)$, which has abilities to discover the non-linear relationships, has recently implemented in asset pricing models.

As an emerging market, there are studies investigating the nonlinearities in Turkish stock market. Aktan and Öztürk (2009) investigated the risk and return relationships of REITs which are listed on Turkish stock market and concluded that the linearity assumption of CAPM is rejected for Turkish market. Çinko (2006) tested the nonlinearity of BIST 100 stock index and concluded that there exist nonlinear relations in returns. For these purposes, to address the gap in the literature about emerging markets and to taking into account the nonlinearity evidences of Turkish stock market, in this study the relationships between Turkish stock market stock indexes and macroeconomic variables over 2003 and 2012 period are examined with Back Propagation ANN.

This paper has four sections starting with introduction and literature review including papers about ANN applications in emerging markets. The second section introduced the ANN method used in this study. In the third section the data and empirical findings are presented. Finally, the last section concludes the paper with remarks.

\section{Literature Review}

Predictability of equity returns is one of the most essential activities in financial modeling. In this regard, establishing accurate financial models for the volatile markets is quite difficult due to the sophisticated character of time series data of the security market.

Within this framework, Artificial Neural Network $(A N N)$ approach would be a robust alternative in estimating the equity returns for the emerging markets, so that ANN is a prospering time series forecasting technique in the financial modeling.

Although there are numerous empirical studies which investigate the stock market movements of the equities in finance literature, there have been carried out limited researches within the emerging markets.

Artificial Neural Network ( $A N N$ ) Models are successful in estimating the direction of the stock market indices. Cao, Leggio and Schniederjans, (2005) analyzed the viability of ANN models in estimating stock market equity price movements for the securities within the Shanghai Stock Exchange and they investigated the forecasting power of univariate and multivariate neural network models with Capital Asset Pricing Model and Fama and French's 3-Factor Model. In further, Cao et al. (2005) had shown that ANN models were superior to the linear models for the mentioned equity time series data.

Yao and Poh (1995) based on the rescaled range analysis they have tried to predict the Kuala Lumpur Stock Exchange (KLSE) index are by Back Propagation neural network. Their experiment reveals that useful predictions can be made without using the extensive market data or knowledge.

Dai, Wu and $\mathrm{Lu}$ (2012) proposed a time series prediction model by combining nonlinear independent component analysis (NLICA) and neural network to forecast Asian stock markets represented by Japanese and Chinese stock markets. Their results indicate that the proposed stock index prediction model can be a good alternative for Asian stock market indexes.

Dutta, Jha, Laha and Mohan (2006) discussed the modeling of the Indian stock market data using ANN and studied the efficiency of ANN in Bombay stock exchange. They have discussed that their error results are in useful level for such a volatile market.

Andreou, Neocleous, Schizas and Toumpouris (2000) investigated of the effect of different neural network architecture alternatives for predicting the future course of stock prices in the Cyprus Stock Exchange (CSE) market. The influence of various economic and political factors, from both the local and the international scene have also been examined in the study. The main conclusion drawn is that the CSE market is governed by unique conditions which when properly modeled can yield successful predictions.

Tsang, Kwok, Choy, Kwan, and Ng (2007) attempt to build a stock buying/selling alert system using a Back Propagation ANN. The system is tested with data from one Hong Kong stock, The Hong Kong and Shanghai Banking Corporation (HSBC) Holdings. Their empirical results showed that the implemented system was able to predict short-term price movement directions with an overall accuracy of over $74 \%$. In addition, they have 
discussed that fairly good prediction accuracy can be achieved using a Back Propagation network without the use of extensive market data or knowledge.

Son, Noh and Lee (2012) tried to predict the price change of KOSPI-200 index in five minutes in the form of binary classification. They have used four state-of-the-art classifiers and observed that the support vector machines classifier overwhelmed the others when no dimension reduction is applied.

Bahrun and Taib (2009) used the feed forward Back Propagation neural network with Levenberg-Marquardt training algorithm to model the selected Malaysian stocks, namely Maybank and Tenaga. In addition models are simulated for trading using four trading strategies. The results indicate that ANN provides a highly accurate model for the stocks also realizes profitable systems using all four trading strategies.

Alhassan and Misra (2011) tried to forecast the stock prices in the stock market industry in Nigeria using a Weightless Neural Network (WNN) and compared with Single Exponential Smoothing (SES) model. WNN is observed to be more accurate and closer to the real data than those using the SES model.

Diler (2003) applied back propagation algorithm of ANN so as to estimate the direction of the Turkish equity market (ISE XU-100) for the return data of following day.

Eğrioğlu, Aladağ, Yolcu, Uslu and Başaran (2009) had proposed a new method which was based on a feed forward ANN to analyze multivariate high order time series forecasting models.

Hamzaçebi, Akay and Kutan (2009) used ARIMA based ANN approach which includes direct and iterative forecasting model in order to find out the best model for time series data.

Bildirici and Ersin (2009) investigated the forecasting capabilities of the different autoregressive models such as ARCH, GARCH, EGARCH, TGARCH etc. for the Turkish stock market data (ISE XU-100) in 1987-2008. However, these researchers had found out that ANN models could provide significant improvements in the forecasting process for the ISE XU-100 index time series return data.

Güresen, Kayakutlu and Daim (2011) evaluated the effectiveness of ANN models in stock market predictions and contributed to the ANN researches for business implementations of market value calculations.

There are also some empirical studies which compare the forecasting performances of ANN models with other rival prediction models in the Turkish equity markets.

Egeli, Özturan and Badur (2003) analyzed the forecasting capabilities of two ANN models with the Moving Average Model (MA), so that these researchers found out that ANN models were more successful than MA models for estimating the ISE index returns.

Altay and Satman (2005) analyzed the predicting power of ANN and they compared the ANN models with Ordinary Least Square $(O L S)$ regression model which were established for ISE XU-30 and ISE XU-All indices. Besides, Karaatlı, Güngör, Demir and Kalaycı (2005) affirmed that ANN model was superior to linear regression model in terms of root mean square error.

Yümlü, Gürgen and Okay (2005) made a comparison of the predicting performances of volatility in ISE XU-100 index returns for Mixture of Experts $(M o E)$, Multilayer Perceptron $(M L P)$, Recurrent Neural Networks $(R N N)$ and EGARCH models.

Şenol and Özturan (2008) compared ANN models with logistic regression and found out that ANN models could give statistically outperformed results in Turkey for the prediction of stock price direction.

Gökgöz and Sezgin-Alp (2014) have investigated the viability of ANN models in predicting the major Turkish stock market indices (BIST 30, BIST 50 and BIST 100) and they have found out that ANN could provide significant estimation results with allowable MSE scores for both training and testing samples.

It is of great importance to estimate the returns of the risky financial assets in volatile markets. Predicting the stock returns with time-series based forecasting models are quite sophisticated and important challenges in quantitative finance area.

ANN technique has been used as a viable alternative for financial decision makers in modeling the time series data of the capital markets. ANN would give fruitful estimation results since the technique uses the complexity of modeling human brain behavior particularly in financial markets.

Besides, APT model has been successfully applied by academicians and practitioners to reveal the return behaviors of financial assets. APT uses linear multifactor estimation models for the financial time series data. In further, ANN can increase the estimation capacity of a financial market model by providing low mean square errors. In this regard, APT model has been selected as a market model for defining the Turkish security market 
and ANN approach has been applied to increase the forecasting ability of the market model.

On the other side, Borsa İstanbul (İstanbul Stock Exchange) is an emerging and a volatile financial market with approximately USD 269.2 Billion market capitalization. In this regard, estimating the major sectoral market returns of Borsa Istanbul with APT model using ANN has an utmost benefit for financial decision makers who desire to invest in the emerging markets.

In this framework, the rationale behind this empirical study is to estimate the equity returns of the main Turkish sectoral stock market indices under APT model with ANN approach. In this regard, the empirical study includes crucial results for emerging markets since this study would contribute to the literature of equity return estimation using ANN in the asset pricing theory.

\section{Methodology}

\subsection{Artificial Neural Network $(A N N)$}

ANNs are computer programs that mimic biological neural networks. They are similar to the biological neural networks. In ANNs as in human brain system the information passes through each neuron via connections to produce an output. The design of ANNs was motivated by the structure of brain (Svozil, Kvasnička, \& Pospíchal, 1997). In the last decade, they became popular and in the latest literature they are preferred to the classical statistical methods. They have many advantages. First of all they have strong ability to deal with non-linear problems (Ma, Yingying, \& Ningfang, 2010).

They have the ability to extract the main influential factors from large data set, they have few prior assumptions and their learning results can be used in generalization of the problem (Dong, Fataliyev, \& Wang, 2013). The most important feature of ANNs is their ability to learn.

There are different types of ANNs but basic architecture is similar in each type. The Figure 1 illustrates the general structure of a basic ANN. There is one input layer where ANN receives the input information, one or more hidden layers in between input and output layers and one output layer where ANN output is produced. Typically, one hidden layer is used in practice. In each layer there are number of neurons. Each neuron is connected to the other neurons of the next layer. The connections between neurons are characterized by weight coefficients. The weight coefficient reflects the degree of importance given in the connection.

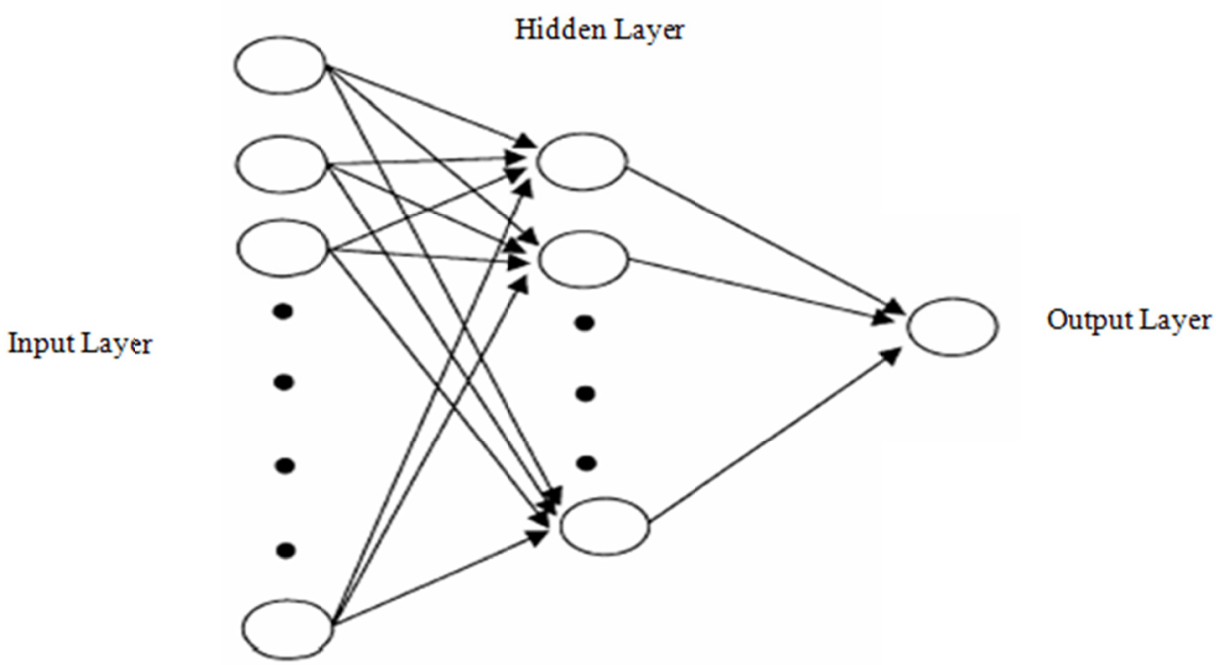

Figure 1. General structure of an ANN

ANN procedure has two phases; training phase and testing phase (Roman \& Jameel, 1996). Before starting the built up the ANN the data should be divided into two as training set and testing set. In training phase, the ANN is executed with random weights and then training data is shown to the network to adjust the weights step by step. When weights are reached to an acceptable level then the network is generalized. This phase is also known as learning. In this context the training algorithm is crucial.

There are mainly two types of training process; supervised and unsupervised training (Svozil et al., 1997). In supervised training the NN knows the desired output and adjust the weights according to minimize the error 
between desired and estimated output. In this algorithm, the result obtained at the output layer is acceptable when it is close to the actual value. In unsupervised training there is no need to know the actual output. The aim of this algorithm is the separation of the data so that they can be used in classification problems. According to the algorithm, the weights are adjusted depending on the input data.

After completing the training/learning of the ANN the performance of the network should be tested by using testing data. In the testing phase, the weights determined in training phase are used to provide new outputs according to the test data. Obtained outputs may be used to see the performance of the network.

In this paper our aim is to establish an estimation model which will predict the stock index returns depending on some macroeconomic factors under APT. According to this purpose, in the paper the multilayer feed forward $(M L F)$ back propagation $(B P)$ learning algorithm is used. The studies in the literature have revealed that the Back Propagation MLF ANN with BP learning is one of the most popular ANN used in finance.

\subsubsection{Multilayer Feed Forward (MLF) Neural Networks}

Feed forward ANNs are popular in modeling the relationships between output and inputs (Che, Chiangm \& Che, 2011). In multilayer ANNs there are one or more hidden layers in between input and output layers. They can be both used in linear and non-linear problems. From input layer the network receives the input and passed to the hidden layer. In hidden layer the information is processed and passed to the other hidden or output layers. In this type of ANN the aim is to minimize the sum of square error. The error can be reduced by adjusting the weights. There are different types of adjustment algorithms. One of the popular alternatives is Back Propagation algorithm.

The MLF neural networks offer some useful properties such as: learning, nonlinearity and robustness however, there are also some disadvantages. For some problems approximation with nonlinear sigmoid function may cause slow convergence problem. In addition, ANNs cannot explain their prediction the process taking place during training of a network is not well interpretable (Svozil et al., 1997).

\subsection{Back Propagation (BP) Training Algorithm}

BP training algorithm is firstly introduced by Rumelhart, Hinton and Williams (1986). It is an iterative process that repeatedly adjusts the connection weights as to minimize the total error of the network. As a result of weight adjustments the internal hidden units come to represent the important features of the task (Rumelhart et al., 1986). BP uses the gradient decent search method to adjust the weights (Che et al., 2011).

Since, it is a kind of MLF ANN there should be at least three layers. Ma et al. (2010) gives the mentioned three layer network as given below. Suppose that " $i$ " represents the input layer, " $j$ " represents the hidden layer and " $k$ " represents the output layer.

And also suppose that,

$$
\begin{aligned}
& w_{i j} \text { is the weight from } i^{\text {th }} \text { input neuron to } j^{\text {th }} \text { hidden neuron, } \\
& v_{j k} \text { is the weight from } j^{\text {th }} \text { hidden neuron to the output layer, } \\
& x_{i} \text { is the } i^{\text {th }} \text { input }(i=1, \ldots, m), \\
& y_{j} \text { is the } j^{\text {th }} \text { output of hidden layer }(j=1, \ldots, n), \\
& \hat{o}_{k} \text { is the } k^{\text {th }} \text { output of the ANN }(k=1, \ldots, s), \\
& o_{k} \text { is the actual value. }
\end{aligned}
$$

In this algorithm the aim is to reduce the overall error of the network given in Equation 1 by adjusting the weights.

$$
E=\frac{1}{2} \sum_{k=1}^{s}\left(\hat{o}_{k}-o_{k}\right)^{2}
$$

The output of the hidden layer depends on the input information and obtained as Equation 2.

$$
y_{j}=f\left(\sum_{i=1}^{m}\left(\mathrm{w}_{i j} x_{i}-\theta_{j}\right)=f\left(\text { net }_{j}\right)\right.
$$

The output of the NN from output layer depends on the output of hidden layer indirectly depends on the input information and obtained as Equation 3. 


$$
\hat{o}_{k}=f\left(\sum_{j=1}^{n}\left(v_{i j k} y_{j}-\theta_{k}\right)=f\left(\text { net }_{k}\right)\right.
$$

Here, the $\theta_{j}$ and $\theta_{k}$ are the threshold values of hidden and output layers, $\mathrm{f}($.$) is the transfer function that should be$ a differentiable function since in BP the weight adjustment process uses gradient decent search method. In practice, generally the sigmoid function given in Equation 4 is used as a transfer function.

$$
f(n e t)=\frac{1}{1+\exp (-n e t)}
$$

After all training sample is shown to the network and outputs are obtained, the overall error of the network should be evaluated and compared with the desired value. If the total error did not converge to the desired value the weight adjustment is needed. The following weight adjustment is used in BP.

$$
\begin{aligned}
& w_{i j}{ }^{t+1}=w_{i j}{ }^{t}-\lambda\left(\frac{\partial E}{\partial w_{i j}}\right) \\
& v_{j k}^{t+1}=v_{j k}{ }^{t}-\lambda\left(\frac{\partial E}{\partial v_{j k}}\right)
\end{aligned}
$$

In this weight adjustment process the obtained gradient will be as given in Equation 7 and Equation 8 (Ma et al., 2010).

$$
\begin{gathered}
\Delta w_{i j}=-\lambda\left(\frac{\partial E}{\partial w_{i j}}\right)=\lambda \delta_{j}^{\prime} x_{i} \\
\Delta v_{i j}=-\lambda\left(\frac{\partial E}{\partial v_{j k}}\right)=\lambda \delta_{k}^{\prime} y_{j}
\end{gathered}
$$

Here, $\lambda>0$ is the learning coefficient and $\delta^{\prime}$ term represents the product of the error with derivative of the transfer function. In BP the algorithm may find the local minimum of the overall error. To prevent this momentum method can be used. In momentum method the gradient is modified as Equation 9 and Equation 10

$$
\begin{aligned}
& \Delta{w_{i j}{ }^{t+1}}^{2}=(1-\alpha) \lambda \delta_{j}^{\prime} x_{i}+\alpha \Delta w_{i j} \\
& \Delta v_{j k}{ }^{t+1}=(1-\alpha) \lambda \delta_{k}^{\prime} y_{j}+\alpha \Delta w^{t}{ }_{j k}
\end{aligned}
$$

Here, $\alpha$ is the momentum coefficient. To understand the BP algorithm we can use the following steps (Che et al., 2011).

Step 1 is the normalization of the data. This process helps to normalize the minimum and maximum values to a bound (Dong et al., 2013). Normalization of the data is preferred to increase the performance of ANN. Inputs are generally in different scales and when sigmoid function is used as a transfer function the expected output should be reduced in between $[0,1]$ and then should be converted to the original values after produced (Öztemel, 2003).

Step 2 is the separation of the data. Before starting to build the ANN model, the training sample and testing sample should be determined.

Step 3 is the setting of the network parameters. Hidden layers provide the network the generalization ability. However, increasing the number of hidden layer will increase the computation time and may cause memorization of the data instead of learning. In application one or two hidden layers are used (Öztemel, 2003).

The number of neurons in input layer and output layer depend on the number of inputs and outputs but the number of neurons in hidden layer should be determined. It may be determined by trying different numbers and comparing the performance of the network or by expertise. Too much number of hidden layer neurons may slow down the convergence speed and may cause over fitting problem (Che et al., 2011).

Generally, ANNs begin with randomly selected weights but small initial weights in between -1 and 1 or $-0,5$ and 0,5 is recommended (Mehtora, Mohan, \& Ranka, 1997). The learning coefficient is needed for the amount of change of weight. The larger values may lead local solutions however too small values will increase the computation time. Momentum coefficient (Note 1) is very important to find the global solution instead of local minimum of the error. It may be difficult to get rid of local solutions when it is too small. 
Step 4 is showing the training set to the network and calculating the output.

Step 5 is calculating the error values and comparing it with the acceptance level. If the error of the network did not converge to the acceptance level the weight adjustment will be needed. The Step for after weight adjustment and Step 5 will be repeated until the error converges to the acceptance level.

Step 6 is the performance evaluation of the ANN with testing sample.

\section{Data and Empirical Findings}

To identify the relationships between the sectoral indices and macroeconomic variables quarterly data covering 2003 and 2012 is used. The sample consists of main sectoral indices (Note 2) such as: BIST-SERV, BIST-REIT, BIST-FIN, BIST-IND and BIST-TECH that are listed on BIST. Since, some of the macroeconomic variables are determined quarterly the values Gross Domestic Product (GDP), inflation, oil prices, exchange rates, logarithmic returns of interest rates are all arranged as quarterly. The data is obtained from BIST, Turkish Central Bank and Turkish Statistical Institute. The inflation is represented by consumer price index and to represent the exchange rate dollar rate is used.

In this paper, the supervised Multilayer Feed Forward Back Propagation ANN is used to predict the stock indices. In the ANN estimations, the data is divided into two as training set and testing set. Nearly, $80 \%$ of the sample is used as a training data.

As parallel to the relating literature, three layer structure is used which means ANN is built as one input, one hidden and one output layers. Five neurons is used in the input layer and one in the output layer since we have five input macroeconomic factors. For the hidden layer different number of neurons is tried and performances are compared. In further, it is found that fine hidden layer neurons are sufficient. After establishing the ANN architecture for the structure of the neural network, the initial weight is taken as 0.5 , the learning coefficient is taken as 0.01 and momentum coefficient is taken as 0.2 .

While transferring information from one layer to another, the sigmoid function (Note 3) has been used. As mentioned before, we have started the BP algorithm with normalization of the data when sigmoid transfer function has been used.

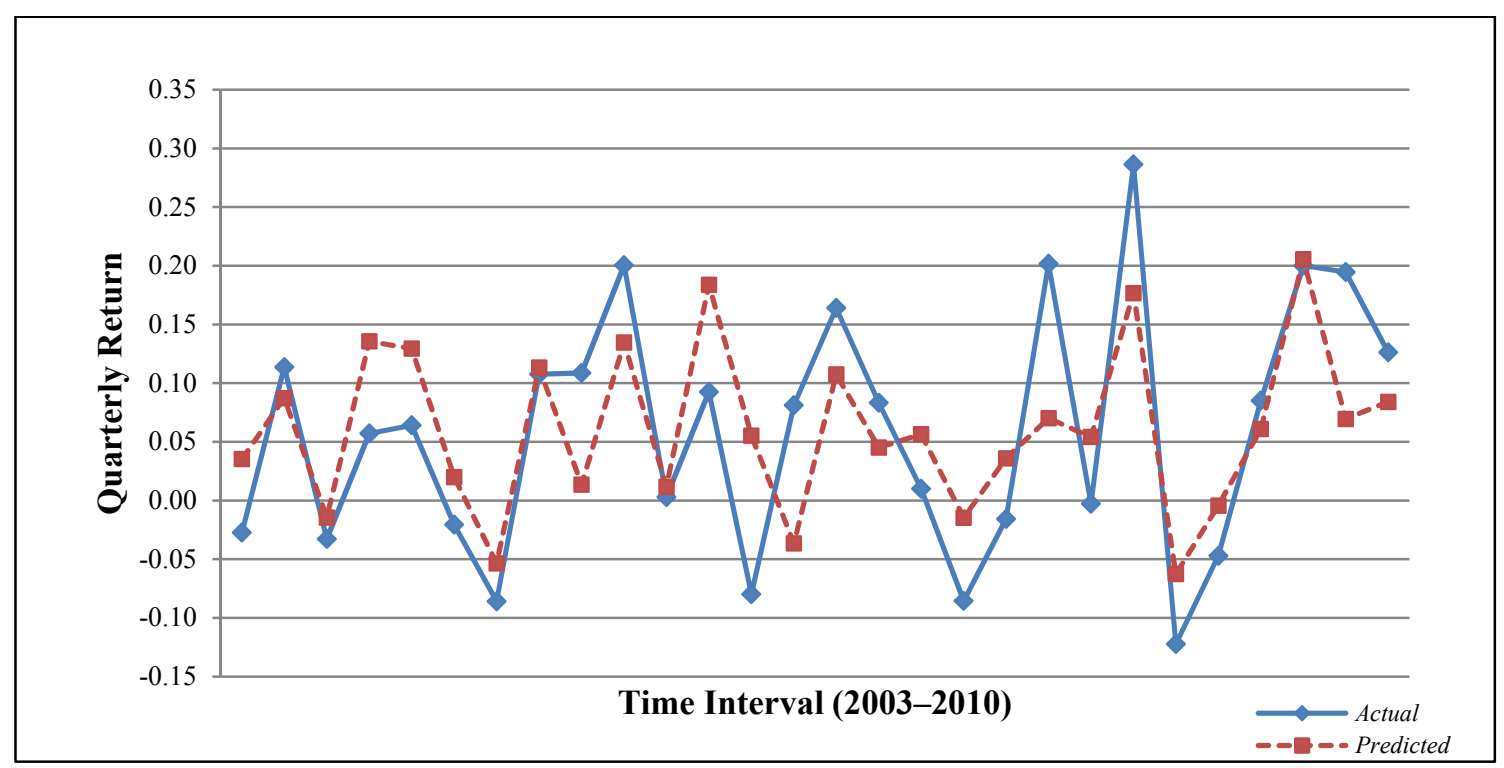

Figure 2. Actual returns and ANN predicted returns for BIST-SERV 


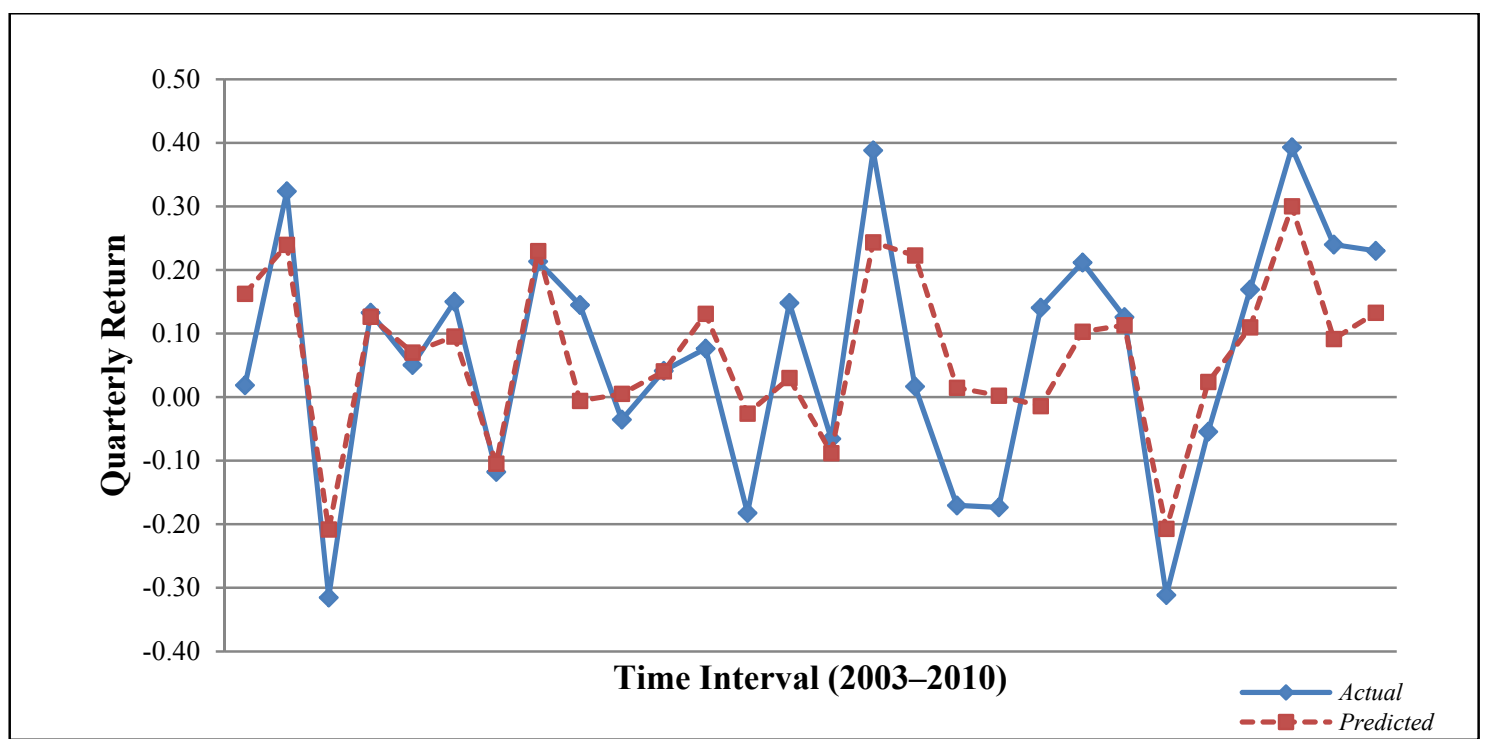

Figure 3. Actual returns and ANN predicted returns for BIST-REIT

The results of ANN performance for training samples are given in Figure 2, Figure 3, Figure 4, Figure 5 and Figure 6. In these graphs, there are actual and estimated returns of BIST-SERV, BIST-REIT, BIST-FIN, BIST-IND and BIST-TECH sectoral indices respectively for the training data. Since data is limited the testing samples graphs are not given here.

As illustrated in graphs, the ANN outputs are closer to the actual returns. Then, we may conclude that ANN captures the pattern of the data. In other words for the Turkish stock market ANN is efficient to learn the market movements. However, just looking at the graphs of the training data is not sufficient to say the success of the method. Investigating the criteria taking into account the error term between actual and predicted return for both training and testing sample will be more reliable. In this study, the mean square error (MSE) is used to evaluate the performances.

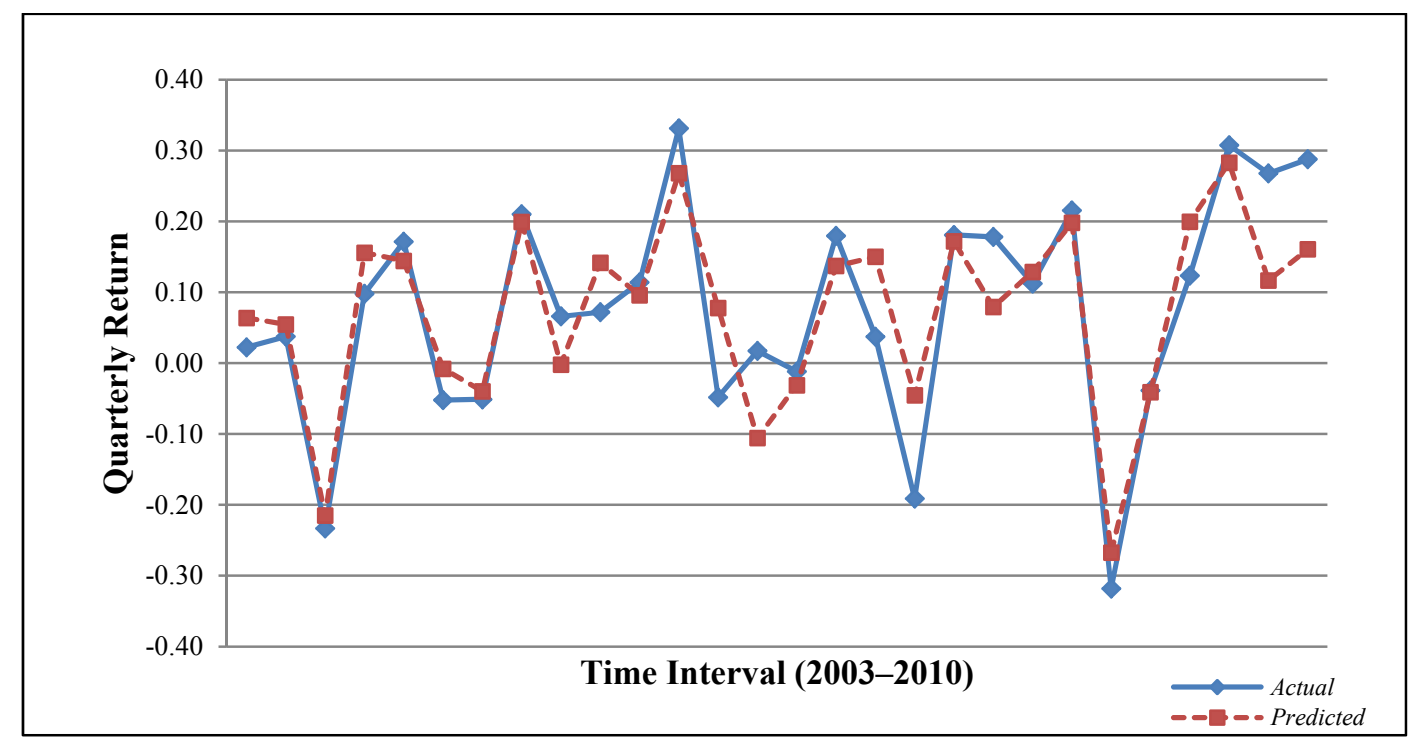

Figure 4. Actual returns and ANN predicted returns for BIST-FIN 


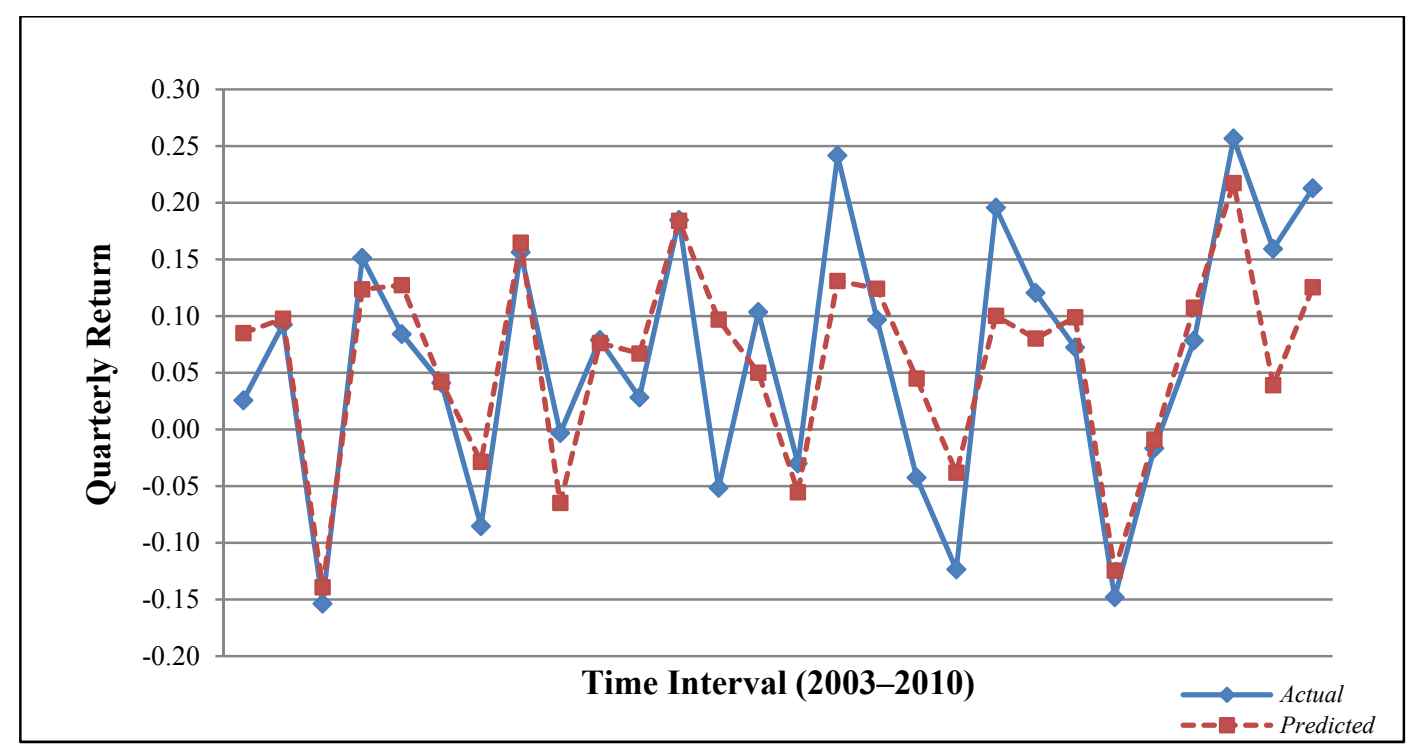

Figure 5. Actual returns and ANN predicted returns for BIST-IND

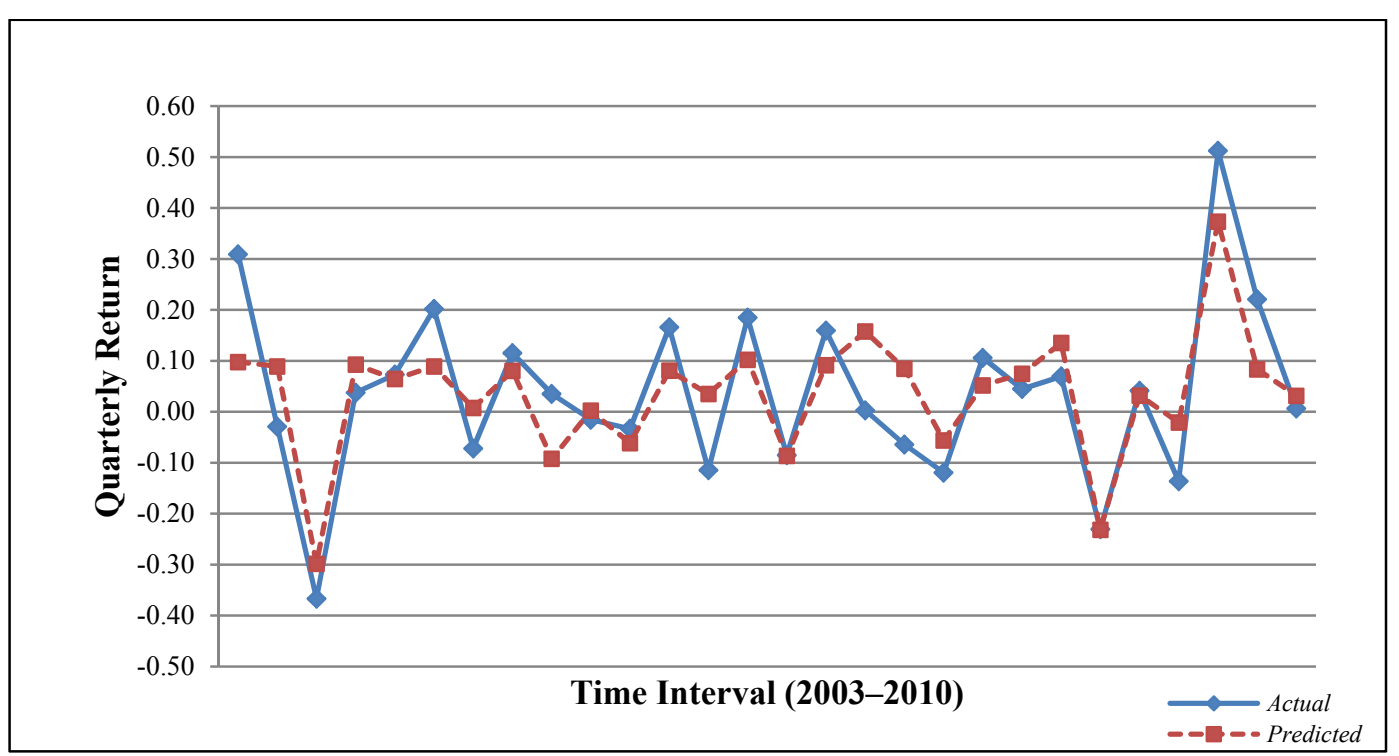

Figure 6. Actual returns and ANN predicted returns for BIST-TECH

As illustrated in Table 1 there are the MSE results for training and testing sets. The MSE results for training set are in between 0.004 and 0.005 which indicates the BP network can effectively train the stock market returns.

The MSE results for testing data are in between 0.03 and 0.04 . These results are not as good as training case however they are in acceptable limits. We have limited data set including 38 samples, since we need to use quarterly data the training data. The testing results have demonstrated acceptable performance means we can use BP network in predicting the Turkish stock market returns.

Table 1. MSE results for both training and testing samples for the ANN estimations

\begin{tabular}{ccc}
\hline Stock Market Indices & Training Sample (MSE Score) & Testing Sample (MSE Score) \\
\hline BIST-SERV & 0.00509 & 0.0296 \\
BIST- $R E I T$ & 0.01194 & 0.0886 \\
BIST-FIN & 0.005288 & 0.0853 \\
BIST-IND & 0.00375 & 0.0528 \\
BIST-TECH & 0.00911 & 0.0992 \\
\hline
\end{tabular}


In addition to the performance measure MSE scores and Figure 1, Figure 2 and Figure 3 showing the actual and predicted values, we have also conducted statistical tests to compare the distributions of the actual and predicted values both for training and testing sets. In this statistical hypothesis test the hypothesis are as following.

$H_{0}$ : There are no differences between actual returns and returns obtained from BP network.

$H_{a}$ : There exist differences between actual returns and returns obtained from BP network.

While testing this hypothesis independent sample t-test is used. The test results are given in Table 2 and Table 3 respectively. For both testing and training sample the $t$-test $P$-significance values for each stock indices are smaller than the significance level $\alpha=0.05 H_{o}$ indifference hypothesis cannot be rejected.

As a result, it is concluded that the predicted returns of $B P$ for both training set and testing set and actual returns are compliant with each other.

\section{Conclusion}

In this empirical study we have estimated the equity returns of the main Turkish stock market indices under APT model with ANN approach. In this regard, the feed forward multi layer Back Propagation Neural Network has been used to forecast the main stock index returns for 2003-2012 period in Turkey. To test the prediction performance of the ANN the method, the main stock indices BIST100, BIST50 and BIST30 has been used to represent the Turkish stock market.

According to the ANN estimations, the results have revealed that ANN estimation approach would be a significant alternative and provide accurate forecasting results with low mean square error values for both in sample and out of sample cases.

We have achieved to allowable MSE scores for both training and testing samples for the period of 2003-2012 in BIST. Besides, empirical results of the main Turkish sectoral stock market indices have shown similar results with Gökgöz and Sezgin-Alp (2014). Thus, we may conclude that ANN estimations could give significant results in forecasting the Turkish asset prices.

Consequently, this study provides crucial results in the frame of arbitrage pricing theory so that ANN can be a viable alternative in predicting the Turkish stock market as an emerging market.

\section{References}

Alhassan, J. K., \& Misra, S. (2011). Using a weightless neural network to forecast stock prices: a case study of nigerian stock exchange. Scientific Research and Essays, 6(14), 2934-2940. http://dx.doi.org/10.5897/SRE10.1040

Altay, E., \& Satman, H. M. (2005). Stock market forecasting: artificial neural network a linear regression comparison in an emerging market. Journal of Financial Management and Analysis, 18(2), 18-33.

Andreou, A. S., Neocleous, C. C., Schizas, C. N., \& Toumpouris, C. (2000). Testing the predictability of the Cyprus Stock Exchange: The case of an emerging market. Proceedings of the International Joint Conference on Neural Networks, 360-365. http://dx.doi.org/10.1109/IJCNN.2000.859422

Bahrun, P. N., \& Taib, M. N. (2009). Selected Malaysia stock predictions using artificial neural network. 5th International Colloquium on Signal Processing \& Its Applications, 428-431. http://dx.doi.org/10.1109/CSPA.2009.5069265

Bildirici, M., \& Ersin, Ö. Ö. (2009). Improving forecasts of GARCH family models with the artificial neural networks: an application to the daily returns in İstanbul Stock Exchange. Expert Systems with Applications, 36, 7355-7362. http://dx.doi.org/ 10.1016/j.eswa.2008.09.051

Cao, Q., Leggio, K. B., \& Schniederjans, M. J. (2005). A comparison between Fama and French's model and artificial neural networks in predicting the Chinese stock market. Computers and Operations Research, 32 , 2499-2512. http://dx.doi.org/ 10.1016/j.cor.2004.03.015

Chamberlain, G., \& Rothschild, M. (1983). Arbitrage, factor structure, mean-variance analysis and large asset market. Econometrica, 51, 1281-1304. http://dx.doi.org/10.2307/1912275

Che, Z. G., Chiang T. A., \& Che, Z. H. (2011). Feed-forward neural networks training: A comparison between genetic algorithm and back-propagation learning algorithm. International Journal of InnovativeComputing, Information and Control, 7(10), 5839-5850.

Chen, N., Roll, R., \& Ross, S. A. (1986). Economic forces and the stock market. Journal of Business, 59, 383403. http://dx.doi.org/10.1086/296344 
Çinko, M. (2006). Linearity test for İstanbul Stock Exchange. İstanbul Üniversitesi İktisat Fakültesi Ekonometri ve İstatistik Dergisi Ekonometri ve İstatistik, 3, 12-11.

Dai, W., Wu, J. Y., \& Lu, C. J. (2012). Combining nonlinear independent component analysis and neural network for the prediction of Asian stock market indexes. Expert Systems with Applications, 39, 4444-4452. http://dx.doi.org/ 10.1016/j.eswa.2011.09.145

Diler, A. İ. (2003). Forecasting the direction of the ISE national-100 index by neural networks back propagation algorithm. The ISE Review, 7(25-26), 65-81.

Dong, G., Fataliyev, K., \& Wang, L. (2013). One-step and multi-step ahead stock prediction using back propagation neural networks (pp. 10-13). 9th International Conference on Information, Communications and Signal Processing (ICICS 2013). http://dx.doi.org/ 10.1109/ICICS.2013.6782784

Dutta, G., Jha, P., Laha, A. K., \& Mohan, N. (2006). Artificial neural network models for forecasting stock price index in the Bombay Stock Exchange. Journal of Emerging Market Finance, 5(3), $283-295$. http://dx.doi.org/ 10.1177/097265270600500305

Egeli, B., Özturan, M., \& Badur, B. (2003). Stock market prediction using artificial neural networks. In Proceedings of the $3^{\text {rd }}$ Hawaii International Conference on Business, Honolulu, Hawaii.

Eğrioğlu, F., Aladağ, C. H., Yolcu, U., Uslu, V. R., \& Başaran, M. A. (2009). A new approach based on artificial neural networks for high order multivariate fuzzy time series. Expert Systems with Applications, 36, 1058910594. http://dx.doi.org/ 10.1016/j.eswa.2009.02.057

Fama, E. F. (1990). Stock returns, expected returns, and real activity. Journal of Finance, 45, 1089-1108. http://dx.doi.org/10.1111/j.1540-6261.1990.tb02428.x

Ferson, W. E., \& Harvey, C. R. (1991). The variation of economic risk premiums. Journal of Political Economy, 99, 385-415. http://dx.doi.org/10.1086/261755

Gökgöz, F., \& Sezgin-Alp, Ö. (2014). Can artificial neural networks be significant in predicting the Turkish stock market returns? In Proceedings of the $13^{\text {th. }}$ Eurasia Business and Economics Society Conference, İstanbul, Turkey.

Güresen, E., Kayakutlu, G., \& Daim, T. U. (2011). Using artificial neural network models in stock market prediction. Expert Systems with Applications, 38, 10389-10397. http://dx.doi.org/10.1016/j.eswa.2011.02.068

Hamzaçebi, C., Akay, D., \& Kutay, F. (2009). Comparison of direct and iterative artificial neural network forecast approaches in multi-periodic time series forecasting. Expert Systems with Applications, 36, 38393844. http://dx.doi.org/ 10.1016/j.eswa.2008.02.042

Harvey, C. R. (1995). Predictable risk and returns in emerging markets. The Review of Financial Studies, 8(3), 773-816. http://dx.doi.org/10.1093/rfs/8.3.773

Huberman, G. (1982). A simple approach to arbitrage pricing theory. Journal of Economic Theory, 28, $183-191$. http://dx.doi.org/ 10.1016/0022-0531(82)90098-9

Humpe, A. (2007). Macroeconomic variables and the stock market: An empirical comparison of the US and Japan. Unpublished PhD thesis. University of St Andrews, Scotland, UK.

Karaatlı, M., Gungor, I., Demir, Y., \& Kalayci, S. (2005). Estimating stock market movements with neural network approach. Journal of Balikesir University, 2(1), 22-48.

Lintner, J. (1965). The valuation of risk assets and selection of risky investments in stock portfolios and capital budgets. Review of Economics and Statistics, 47, 13-37. http://dx.doi.org/ 10.2307/1924119

Ma, W., Yingying, W., \& Ningfang, D. (2010). Study on stock price prediction based on BP neural network. IEEE, 57-60. http://dx.doi.org/ 10.1109/ICEMMS.2010.5563502

Markowitz, H. (1952). Portfolio selection. The Journal of Finance, 7(1), 77-91.

Mehrotra, K., Mohan, C. K., \& Ranka, S. (1997). Elements of artificial neural networks. The MIT Press.

Mossin, J. (1966). Equilibrium in a capital market. Econometrica, 34, $768-783$. http://dx.doi.org/10.2307/1910098

Öztemel, E. (2003). Neural networks [Yapay sinir ăglari]. Papatya Publishing.

Roll, R., \& Ross, S. A. (1980). An empirical investigation of the arbitrage pricing theory. Journal of Finance, 35 , 
1073-1103. http://dx.doi.org/10.1111/j.1540-6261.1980.tb02197.x

Roman, J., \& Jameel, A. (1996). Back propagation and recurrent neural networks in financial analysis of multiple stock market returns. Proceedings of the 29th Annual Hawaii International Conference on System Sciences, 454-460. http://dx.doi.org/ 10.1109/HICSS.1996.495431

Ross, S. A. (1976). The arbitrage pricing theory of capital assets pricing. Journal of Economic Theory, 13, 341360. http://dx.doi.org/10.1016/0022-0531(76)90046-6

Rumelhart, D. E., Hinton, G. E., \& Williams, R. J. (1986). Learning representations by back-propagating errors. Nature, 323, 533-536. http://dx.doi.org/10.1038/323533a0

Şenol, D., \& Özturan, M. (2008). Stock price direction prediction using artificial neural network approach: The case of Turkey. Journal of Artificial Intelligence, 1, 70-77. http://dx.doi.org/ 10.3923/jai.2008.70.77

Sharpe, W. F. (1964). Capital asset prices: A theory of market equilibrium under conditions of risk. Journal of Finance, 19, 425-442. http://dx.doi.org/10.2307/2977928

Son, Y., Noh, D. J., \& Lee, J. (2012). Forecasting trends of high-frequency KOSPI-200 index data using learning classifiers. Expert Systems with Applications, http://dx.doi.org/10.1016/j.eswa.2012.04.015

Svozil, D., Kvasnička, V., \& Pospíchal, J. (1997). Introduction to multi-layer feed-forward neural networks. $\begin{array}{lllll}\text { Chemometrics and Intelligent } & \text { Laboratory }\end{array}$ http://dx.doi.org/10.1016/S0169-7439(97)00061-0

Tsang, P. M., Kwok, P., Choy, S. O., Kwan, R., \& Ng, S. (2007). Design and implementation of NN5 for Hong Kong Stock price forecasting. Engineering Applications of Artificial Intelligence, 20, 453-461. http://dx.doi.org/10.1016/j.engappai.2006.10.002

Yao, J., \& Poh, H. L. (1995). Forecasting the KLSE index using neural networks. Proceedings of the IEEE International Conference on Neural Networks, 1012-1017. http://dx.doi.org/ 10.1109/ICNN.1995.487559

Yümlü, S., Gürgen, S. F., \& Okay, N. (2005). A comparison of global, recurrent and smoothed-piecewise neural models for Istanbul Stock Exchange (ISE) prediction. Pattern Recognition Letters, 26(13), $2093-2103$. http://dx.doi.org/10.1016/j.patrec.2005.03.026

\section{Notes}

Note 1. The momentum coefficient adds a fraction of the previous weight update to the current one. The momentum parameter is used to prevent the system from converging to a local minimum or saddle point.

Note 2. BIST-SERV represents services, BIST-REIT represents real esitate investment trusts, BIST-FIN represents financials, BIST-IND represents industrials and BIST-TECH represents technology sectors.

Note 3. Sigmoid function is a mathematical function having an " $S$ " shape which refers to the special case of the logistic-function.

\section{Appendix A}

Table A1. Hypothesis Test Results for Training Samples

\begin{tabular}{|c|c|c|c|c|c|c|c|c|c|c|}
\hline & & \multicolumn{2}{|c|}{ Levene's Test } & \multicolumn{7}{|c|}{$t$-test for Equality of Means } \\
\hline & & \multirow[t]{2}{*}{$F$} & \multirow[t]{2}{*}{ Sig. } & \multirow[t]{2}{*}{$t$} & \multirow[t]{2}{*}{$d f$} & \multirow{2}{*}{$\begin{array}{l}\text { Sig. } \\
\text { (2-tailed) }\end{array}$} & \multirow{2}{*}{$\begin{array}{l}\text { Mean } \\
\text { Diff. }\end{array}$} & \multirow{2}{*}{$\begin{array}{l}\text { Std. Error } \\
\text { Diff. }\end{array}$} & \multicolumn{2}{|c|}{$\begin{array}{c}95 \% \text { Confidence } \\
\text { Interval }\end{array}$} \\
\hline & & & & & & & & & Lower & Upper \\
\hline \multirow{2}{*}{ BIST-SERV } & Equal variances assumed & 5.826 & 0.019 & -0.058 & 54 & 0.954 & -0.00139 & 0.02391 & -0.04932 & 0.04655 \\
\hline & Equal variances not assumed & & & -0.058 & 47.076 & 0.954 & -0.00139 & 0.02391 & -0.04948 & 0.04671 \\
\hline \multirow{2}{*}{ BIST-REIT } & Equal variances assumed & 4.459 & 0.039 & -0.039 & 54 & 0.969 & -0.00166 & 0.04303 & -0.08794 & 0.08461 \\
\hline & Equal variances not assumed & & & -0.039 & 47.163 & 0.969 & -0.00166 & 0.04303 & -0.08823 & 0.0849 \\
\hline \multirow{2}{*}{ BIST-FIN } & Equal variances assumed & 0.723 & 0.399 & 0.014 & 54 & 0.989 & 0.00055 & 0.03915 & -0.07794 & 0.07904 \\
\hline & Equal variances not assumed & & & 0.014 & 52.266 & 0.989 & 0.00055 & 0.03915 & -0.078 & 0.0791 \\
\hline \multirow{2}{*}{ BIST-IND } & Equal variances assumed & 2.348 & 0.131 & 0.007 & 54 & 0.995 & 0.00018 & 0.02726 & -0.05447 & 0.05483 \\
\hline & Equal variances not assumed & & & 0.007 & 50.637 & 0.995 & 0.00018 & 0.02726 & -0.05456 & 0.05491 \\
\hline \multirow{2}{*}{ BIST-TECH } & Equal variances assumed & 2.108 & 0.152 & 0.009 & 54 & 0.993 & 0.00037 & 0.03979 & -0.07941 & 0.08015 \\
\hline & Equal variances not assumed & & & 0.009 & 48.982 & 0.993 & 0.00037 & 0.03979 & -0.07959 & 0.08034 \\
\hline
\end{tabular}


Table A2. The Hypothesis Test Results for Testing Samples

\begin{tabular}{|c|c|c|c|c|c|c|c|c|c|c|}
\hline & & \multicolumn{2}{|c|}{ Levene's Test } & \multicolumn{7}{|c|}{$t$-test for Equality of Means } \\
\hline & & \multirow[t]{2}{*}{$F$} & \multirow[t]{2}{*}{ Sig. } & \multirow[t]{2}{*}{$t$} & \multirow[t]{2}{*}{$d f$} & \multirow{2}{*}{$\begin{array}{l}\text { Sig. } \\
\text { (2-tailed) }\end{array}$} & \multirow{2}{*}{$\begin{array}{l}\text { Mean } \\
\text { Diff. }\end{array}$} & \multirow{2}{*}{$\begin{array}{l}\text { Std. Error } \\
\text { Diff. }\end{array}$} & \multicolumn{2}{|c|}{$\begin{array}{c}\text { 95\% Confidence } \\
\text { Interval }\end{array}$} \\
\hline & & & & & & & & & Lower & Upper \\
\hline \multirow{2}{*}{ BIST-SERV } & Equal variances assumed & 5.494 & 0.031 & -0.923 & 18 & 0.368 & -0.05112 & 0.05551 & -0.16785 & 0.06541 \\
\hline & Equal variances not assumed & & & -0.923 & 13.573 & 0.372 & -0.05112 & 0.05551 & -0.17063 & 0.06820 \\
\hline \multirow{2}{*}{ BIST-REIT } & Equal variances assumed & 0.734 & 0.403 & -1.244 & 18 & 0.230 & -0.11460 & 0.09214 & -0.30818 & 0.07898 \\
\hline & Equal variances not assumed & & & -1.244 & 16.640 & 0.231 & -0.11460 & 0.09214 & -0.30932 & 0.08012 \\
\hline \multirow{2}{*}{ BIST-FIN } & Equal variances assumed & 2.777 & 0.113 & -0.487 & 18 & 0.632 & -0.04952 & 0.10168 & -0.26313 & 0.16409 \\
\hline & Equal variances not assumed & & & -0.487 & 14.137 & 0.634 & -0.04952 & 0.10168 & -0.26739 & 0.16835 \\
\hline \multirow{2}{*}{ BIST-IND } & Equal variances assumed & 2.042 & 0.170 & -0.690 & 18 & 0.499 & -0.04975 & 0.07211 & -0.20125 & 0.10175 \\
\hline & Equal variances not assumed & & & -0.690 & 14.355 & 0.501 & -0.04975 & 0.07211 & -0.20406 & 0.10455 \\
\hline \multirow{2}{*}{ BIST-TECH } & Equal variances assumed & 4.093 & 0.058 & -0.138 & 18 & 0.892 & -0.01577 & 0.11404 & -0.25535 & 0.22382 \\
\hline & Equal variances not assumed & & & -0.138 & 16.040 & 0.892 & -0.01577 & 0.11404 & -0.25747 & 0.22594 \\
\hline
\end{tabular}

\section{Copyrights}

Copyright for this article is retained by the author(s), with first publication rights granted to the journal.

This is an open-access article distributed under the terms and conditions of the Creative Commons Attribution license (http://creativecommons.org/licenses/by/3.0/). 